\title{
The Internal and External Customer Focused Process Improvement and the Performance Analysis Studies in Healthcare Systems
}

\author{
Pirıl Tekin(D), Rizvan Erol(iD) \\ Cukurova University (Turkey) \\ ptekin@,cu.edu.tr, rerol@,cu.edu.tr
}

Received: September 2016

Accepted: April 2017

\section{Abstract:}

Purpose: The main contribution of this paper is to generate an optimum solution for capacity planning and appointment scheduling issues, which are frequently encountered in clinical flows with various route and treatment periods at dental hospitals.

Design/methodology/approach: It is essential to define the system well in order to ensure that the working staff and patients use their time very efficiently and that the process flows continuously. By having examined a sample healthcare system through the help of a study addressed in such context, studies on process improvement in line with the dissatisfactions of the working staff and patients have been carried out. Within the scope of the study, the operation of 7 Departments in a dental hospital undergoing a treatment process have been reviewed and examined. The problems encountered as result of the observations made are discussed in detail, and formerly and recently designed system performance analyses are conducted by having performed the respective process improvement studies. The relevant samplings of this study are modeled via the Arena Simulation Program. The data of the previous four months is used in the parameters, which are used through the modellings. The system data are entered by taking into account seasonal characteristics of the data.

Findings: The analyses are made as a consequence of such study that has been addressed, it is established that the efficiency of the internal customers of the hospital increases substantially, and 
that the waiting durations of the dental patients decrease and in turn, the external customer satisfaction increases drastically.

Research limitations/implications: Under the scope of the present study, 7 different treatment processes are analysed in a dental hospital in Cukurova Region with a significant patient potential. The treatment clinics present in the hospital are radiology, periodontology, surgery, treatment, orthodontics and prosthesis. These clinics run their own appointment and treatment system independently. Thus, the study has limited with five departments among 7.

Originality/value: With this study, given the flow of different existing treatment processes belonging to patients are optimized, and also the continuity of the system is ensured by minimizing the patient waiting times within the existing system.

Keywords: healthcare systems, performance analysis, process improvement, patient satisfaction, productivity

\section{Introduction}

Health systems have crucial importance as they have humanist approach at their core. Fast developing technologies and increasing competition trend make the system cycle even more difficult than ever. This systematical competition naturally has its effects on the expectations of customers. Looking historically, it can be seen that the concept of quality is developed in order to decrease the impact of competition on the expectations of customers. In time, the concept of quality is replaced with the adoption of system approaches aiming at impressing the customers, rather than setting standards for quality.

Based on human health and customer satisfaction, health systems need to encompass integrity of services requiring the highest sensitivity and balance. For this reason, there is a sensitive line between management and customer satisfaction. The competition in the health sector, which is even getting stronger particularly in the recent years, led to the dominance of a management approach centered on external customer (Alparslan, Cağcağ \& Eğrioğlu, 2010). Due to the dominance of this point of view having direct impact on the application of the patients to the institutions, internal customers and systematical errors may be overlooked from time to time. To this end, it is utmost important for the hospital managements to increase the patient potential and ensure the sustainability of the institution under optimum circumstances (Ogulata \& Erol, 1998). The speedy and continuous transformation in the health sector made management of health institutions develop a dynamic structure. For this reason, hospital 
managements need to accommodate all activities under its umbrella and hold a capacity of thinking in a multi-dimensional manner in order to be able to adapt themselves to these speedy changes in the sector.

The management of a successful hospital should develop continuous development approaches against the mistakes which occur naturally as a result of the nature of the health services. Evaluation of the system by hospital managers through two different points of views for two different customers' types present in the system would even enhance the success (Ceschia \& Schaerf, 2011; Kisaer \& Karabacakoğlu, 2004; Shao, 2011). Making the hospital personnel, who are defined as internal customers, work with the highest productivity positively affects the overall performance of the hospital and boost the satisfaction level of the patients who are defined as external customers as well. The increase in the satisfaction level of the external customers would enhance the preferability of the hospital by them under competitive conditions. The satisfaction of internal customers triggers hospital preferences of external customers indirectly. Occurring in a cycle and interacting with each other continuously, these concepts should be managed in the most efficient way in order to ensure the continuity of the process flow (Tekin \& Erol, 2016).

Dynamic nature of health systems and its accommodation of various processes and disciplines turn hospital management into a more difficult task. This is to say that these conditions make it more complicated to plan and inspect the system within certain intervals and manage the process. Inadequate amounts of resources and/or inefficient use of existing resources, which are attributable to both state policies and hospital management policies, and some systemic problems, such as poor treatment coordination among clinics of a hospital, intensity of patients, uncertainty of treatment durations, high number of applications to the emergency department lead to bottlenecks in process flow in hospitals. Increasing hospital queues caused by the above-mentioned factors and the increase in the treatmentrelated problems lead to an inevitable increase in the quality of services provided. This loss in quality imposed direct and negative impact on patients which are defined as external customers.

Now that the long queues in the system constitute problem both for the service provider organization and patients, the system needs to be evaluated from two different perspectives. From the perspective of users of service, in other words, external customers, the most important concept is timely delivery of services. More specifically, it is necessary for a health organization which should keep sufficient number of physicians and materials available to meet the service demand instantly and make the respective treatment demand plans. As for the perspective of service provider organization, it is necessary to plan efficient use of the existing resources and all treatment processes, and develop appointment scheduling systems if needed. Long waiting period for treatments is a very unwanted situation in a human-based activity. For this reason, determination of appointment system that fits best to the context is very important for all organizations. As a response to such factors, process improvements would enhance the 
performance of hospitals and internal customers (physicians and treatment support staff), as well as increasing the satisfaction of external customers (patients).

All objectives of the present study can be listed as follows: The appointment system will be re-regulated in consideration of the inter-clinics coordination to ensure sustainability of treatment processes. The capacities of all respective clinics will be evaluated one by one and a balance will be achieved in the distribution of internal customers over departments. A balance will also be achieved among the appointment quotas of clinics. The system will be improved so as to optimize the waiting period in which external customers/patients wait to receive treatment. The second part of the present study organized to serve to the above-mentioned purposes includes analysis of the literature in terms of the scheduling and simulation practices applied under quality, queue and appointment systems. The following part of the study analyzes the system and methodology applied in the hospital which accommodates the present study. As for the fourth part, details of the study and its application are presented. The paper ends with conclusion and discussion parts of the study.

\section{Review of the Literature}

In literature, different types of system simulation topologies are studied by researchers. The most commonly used topology is the simulation just for one department. Generally in literature, patients coming and departure time are examined for only one department. For this purpose, different simulation modeling has been developed to provide maximum capacity (Dacosta, Baesler \& Jahsen, 2003; Kapamara, Sheibani, Petrovic, Haas \& Reeves, 2007; Kim \& Horowitz, 2002). The performance bottlenecks of patients are identified via taking into account all criterias such as occupancy rate, queue formation, queue lengths and waiting times of patients. Moreover, the new system is designed to allow to minimize patient waitings after determining the bottleneck. Also, appointment management system roadmap has been designed in some publications and future opportunities for the evaluation of the system are provided for new studies (Tekin \& Erol, 2016).

In a study conducted by Kim and Horowitz (2002), bed number planning was made for patients in intensive care units. To this end, new scheduling periods were determined, and a comparison was made between the new system and the existing system. System productivity was tested through simulation program. The performance criteria used were the number of patients to whom the hospital rejected to provide treatment, the number of patients on whom the hospital rejected to make surgery, rates of bed utilization, and average number of patients waiting in the queue. In their study, Dacosta et al. (2003) sought to balance the number of uncertain demands in the applications made to emergency service of a private hospital in 2003. Significance levels of the resources used by the system to meet the expected 
demand and their impact on the process were tested via experimental design. As a result of different replications performed through simulation, it was concluded that the most important factors affecting the patients' waiting time are some parameters intervening the system externally.

The performance analysis performed by Kisaer and Karabacakoğlu (2004) included cost-effectiveness analyses of the organization. Basic performance indicators of the hospital were determined. In addition, work load of internal customers of the organization (dentists) and their performance levels were identified. Nguyen, Six, Antonoli, Glemain, Potel, Lombrail et al. (2005) conducted a study on the surgical department and internal diseases department of an organization in 2005. The study set out to identify the optimum bed capacity by evaluating the parameters of patients referring to the concerned departments on emergency basis and the bed occupancy rates. The solution of the system was modeled by using a simulation program. The lost patients which were referred to other hospitals due to the overloaded status of the system were also taken into consideration. At the end of the study, optimum capacity calculation was made.

Cochran and Bharti (2006), in their study, applied discrete event simulation and queuing model in order to optimize the bed capacities of all units in a hospital. The two-stage system established was modeled by using simulation program. The external customer flow of the hospital was analyzed and bottlenecks were identified. A new system which would minimize the patients' waiting time was developed under this study. In another study, Gupta and Denton (2008) underlined the importance of the appointment scheduling in health care. The opportunities and threats of the appointment scheduling and the existing system were analyzed in detail. Furthermore, a road map of appointment management system was developed and the importance of future opportunities for the current practices was identified. Kapamara et al. (2007) sought to minimize the patient queues for more than one treatment device during cancer treatments by remodeling of system. They identified bottlenecks and re-planned the flows.

In his dissertation Yalçin (2009) applied simulation and optimization techniques as decision support tools. In this study, Yalçin aimed to minimize treatment processes of external customers and maximize patient flow. The experimental results of the modeling and system design evidenced that the new system will decrease the average patient's time in the hospital approximately by $28 \%$, by using the existing resources of hospital. In another study conducted by Soyarslan, Karaca and Tamyuksel (2010), the authors tried to identify the causes of the patient queue system in an emergency unit of a hospital. They modeled the system by using simulation and the process improvements were analyzed in detail. In a similar his study, Shao (2011) examined the arrival uncertainties of patients without appointments in one of the departments constituting a bigger bottleneck for the hospital. An accurate planning of queues for internal and external customers was achieved through the new process design. 
In the present study, treatment process in a dental hospital is analyzed, with a view to offer recommendations for the improvement of the system on the basis of the customer complaints. In this sense, the first step is the analysis of the treatment process flow currently applied in 7 departments in the hospital, which would be the basis for future improvement of the treatment process flow in some departments. It is planned that the duties and responsibilities of all personnel will be revised in order to maximize the physicians' performance and increase the rates of treatment on the basis of clinics. In addition, the cycle time which external patients spend in the hospital for treatment is planned to be decreased, which in return would eliminate most of the complaints of the patients in respect to waiting period.

The literature review presents no finding as to the presence of a health system practice where there are process flows which are considered to be independent from each other, but in fact are interconnected and even nested, despite various process improvement actions taken (Tekin \& Erol, 2016). The new process flows developed under the study for the problems are realized in real life situations and the designed system performances are tested with real data. Functionality of the renewed process flows of treatment and their contribution to the system are discussed in the following parts of the paper.

\section{Real System Process Flow}

Under the scope of the present study, 7 different treatment processes are analysed in a dental hospital in Cukurova Region with a significant patient potential. The treatment clinics present in the hospital are radiology, periodontology, surgery, treatment, orthodontics and prosthesis. These clinics run their own appointment and treatment system independently. However, the biggest problem experienced in the hospital is the customers' dissatisfaction with the treatment appointments. The waiting-period, which is prolonging every day, brings about an increase in the number of complaints made to the hospital management. Unmet expectations of the external customers and failure to solve the health problems requiring urgent intervention cause the hospital to suffer loss of patients. The corrective measures taken by the hospital management (such as increasing the patient capacity) proved to be insufficient. This clarified the need to focus the solution recommendations on system improvement (Gupta \& Denton, 2008; Tekin \& Erol, 2016). As a result of the system analyses made, it is found that independent operation of each clinic in the hospital prolonged the number of the treatment days in each clinic.

In the present system, the treatment process flow of all clinics operates independently as can be seen in the Figure 1. The clinics give appointments to patients independently and the coordination among them is unfortunately ignored by the hospital management. For this reason, the patients wait for each clinic to which they apply separately. The biggest difficulty is witnessed in cases where the patient's health problem 
requires a more complicated and different clinical treatments. For this reason, the patients who receive different appointment sequence numbers from different clinics apply for the clinic whose appointment date is the closest. However if the other clinical treatment procedure/operation for which $\mathrm{s} /$ he is waiting to get appointment need to be carried out before the treatment/operation to be applied under the clinic for which s/he holds an appointment, the patient unfortunately has to wait for the other appointments without undergoing the procedure/operation to be provided by the clinic whose appointment is the earliest one.

Dento

Maxillofacial

Radiology

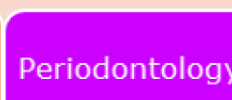

Restorative Dentistry
Ortodontics

Pedodontics

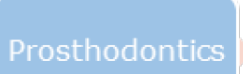

Figure 1. The real system clinics treatment flow

The general process followed by patients applying to the dental hospital in line with their complaints (because of their toothaches) is as follows: A patient applies to the dental hospital for the first time or if s/he applies to the hospital after six months, the patient is referred to Dental and Maxillofacial Radiology directly. General examination is conducted on the patient in Dental and Maxillofacial Radiology. Following general examination, the patient's treatment is planned by this department. The patient applies to the concerned clinic to take an appointment according to the treatment plan. The patient delivers the treatment on the appointment date.

At the end of the treatment, the dentist decides whether the patient needs additional session of treatment. In absence of such a need for further treatment, the patient leaves the system. In the presence of this need, the patient applies to another clinic. The process operates within this cycle. However, the biggest difficulty experienced in this process is that the patient is not referred to clinics within a certain sequence of treatment.

As the clinics do not work in coordination with each other, patients are not able to go to the clinics which they need to visit first due to the intensity of appointments. For this reason, the appointments drop (just like the productivity of internal customers decrease) and external customers prefer to apply to other health-care organizations before their treatments are completed, as they have to wait long queues. The system improvements performed for the purpose of eliminating these hitches and balancing the satisfaction between internal and external satisfaction are clearly detailed in the following parts. 
This causes patient no-shows in the clinics, and increases waiting - periods of the patients for treatment and thus causes an increase in the patients' complaints as well. Furthermore, in such cases, the patient also faces the obligation to reapply to the clinic whose appointment is missed. The systematical mistakes are detected on the basis of the increasing complaints of the patients. The hospital management attempted to solve them. So, how's the patient complaint process occurs?

In the hospital where the study was performed, there are two types of patient complaints. External customers are able to communicate the problems they experience in respect to queues and systematic errors to the internal customers/employees of the hospital verbally. The complaints communicated to the internal customers verbally are recorded by units and submitted to the attention of the upper management. At complaint points located at the most intensive points of the hospital; the patients can write down and deliver their complaints. These complaints are processed by the Quality Department on weekly basis; and they are categorized and then communicated to the upper management during monthly meetings. In this hospital, the primary reason behind this system improvement activity is realization of the upward tendency of patient complaints delivered by the above-mentioned channels in certain categories.

Increasing number of patient complaints has motivated the internal customers to express the problems caused by the systematic problems for them more often in time. Besides, speedy determination in the productivity of internal customers was another factor that compelled the upper management to identify the bottlenecks of the system and re-design the system. This is why the existing system needs to be analyzed in detail in the dental hospital which was targeted by the present study for this purpose. For this reason, the relevance among the treatment processes of different clinics is analyzed and the maps of the treatment processes are revised.

\section{Framework of the Proposed System}

There are various independent treatments in each hospital. However, there is a fact which is ignored in most of the studies in the literature: there are many treatments with parts whose processes are interconnected although they are organizationally independent from each other. The failure to evaluate such cases prolongs the treatment processes of the patients by $10 \%$. Determination of the priority sequence of the treatments offered by different departments would also bring about a drop in the number of the patient complaints (Gupta \& Denton, 2008). In this context, the system improvement study in hand includes the determination of the roadmaps of the treatment processes of all clinics in a dental hospital in consideration of their inter-relevance, which distinguishes it from other studies in the literature (Nguyen et al., 2005; Shao, 2011; Soyarslan et al., 2010). 
The evaluation on the treatment processes performed in the said dental hospital revealed that the general examination conducted in the department of radiology functions as a roadmap for the whole treatment process of the patient. Unfortunately, it is the patients who decide which clinic they will apply in line with their dental complaints and get involve with the appointment system of the concerned clinic. However all other clinics else than the radiology clinic refer the patients who apply the hospital for the first time or the patients whose last treatment is made six months ago and did not apply to the radiology clinic as first resort. Then how can this time loss experienced are minimized in the health institutions for which time is more previous and more urgent interventions are needed?

The biggest deficiency of the previous studies in the literature is the failure to take the clinic treatment interdependencies into account (Yalçin, 2009). As the previous studies focus on the intensity and operation in individual clinics, the system simulations performed unfortunately ignore various process bottlenecks.

Some of the previous studies used real data of a real hospital in their analysis on the physical/resource acquisition, patient satisfaction and increasing productivity in health services. However, although tail models and discrete event simulation are applied on more than one department, the interflow between the departments is ignored in these studies (Cohcran \& Bharti, 2006; Kapamara et al., 2007; Mageshwari \& Kanaga, 2012; Ceschia \& Schaerf, 2011). Despite the oral explanations made on the importance of the appointment scheduling practice and necessity of a roadmap for the appointment management system in various activities, the biggest drawback of the literature is the presence of the studies conducting system simulation due to the complicatedness of the system structure.

It is truly a hard task to solve the problems of appointment scheduling systems which are considered to be very complicated through a simulation software program. For this reason, agent based systems have been generally preferred in recent years (Mageshwari \& Kanaga, 2012). Due to the scarcity of the studies conducted in consideration of the interdependencies among the system flows of various departments, the present study attempted to solve the problems by integrating the dynamic systems to the simulation.

The evaluation on the practices of the concerned dental hospital showed that the radiology department covered all departments and facilitates the operation of the treatment processes. In other words, the start of the flow of the departments for the detailed treatments to be delivered is decided on the basis of the findings of the detailed examination to be performed in this department. There are different treatment stages in each department of the hospital. Administration of examination tasks peculiar to each department is necessary for the detailed treatments of the departments. The examination performed in the radiology department is very important in providing a general diagnosis of the problems of the patients and determination of the treatment units needed. When patients omit this department, which is 
the basic diagnosis center and obtain appointments directly from the departments they choose, it causes an extension approximately by $10 \%$ in their treatment processes.

This means that it is necessary to introduce process roadmaps that would minimize the possibility that the patients choose the department they will apply. Certainly, the patients applying the hospital for specific departments, the patients referred to the hospital following the administration of a treatment administered by another health institution, and the patients who started to receive a treatment from private hospitals, but want to have their treatment in specific clinics of the hospital in a coordinated way need to be excluded from these roadmaps.

The procedure of appointment applications to clinics and the treatment processes may vary depending on such patient groups. A detailed analysis of the practices in the dental hospital in question revealed the necessity to revise the work flow of the clinics as depicted in the Figure 2.

\section{Dento Maxillofacial Radiology}

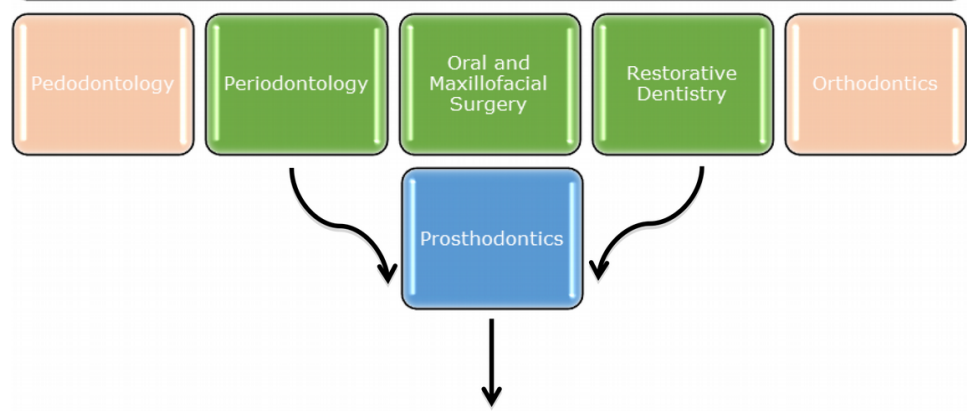

End of Treatment Process

Figure 2. Clinics process flow charts

There are 7 different clinic operations in this hospital as mentioned in previous sections. However, Orthodontics and Pedodontics clinics deliver treatments with independent processes. This is to say that the same clinic physician conduct all treatments, starting from the start to the finalization of the treatment. Therefore each clinic has a separate process that does not need the operation of a different clinic. In other five departments, patients are referred to other departments in line with their treatment planning. Because of this situation, the 2 departments are separeted for the proposed system modelling.

The hospital treatment flows explained in detail in the study performed in 2016 are revised and the clinics which operate interconnected, though they are structurally independent from each other are separated (Tekin \& Erol, 2016). 


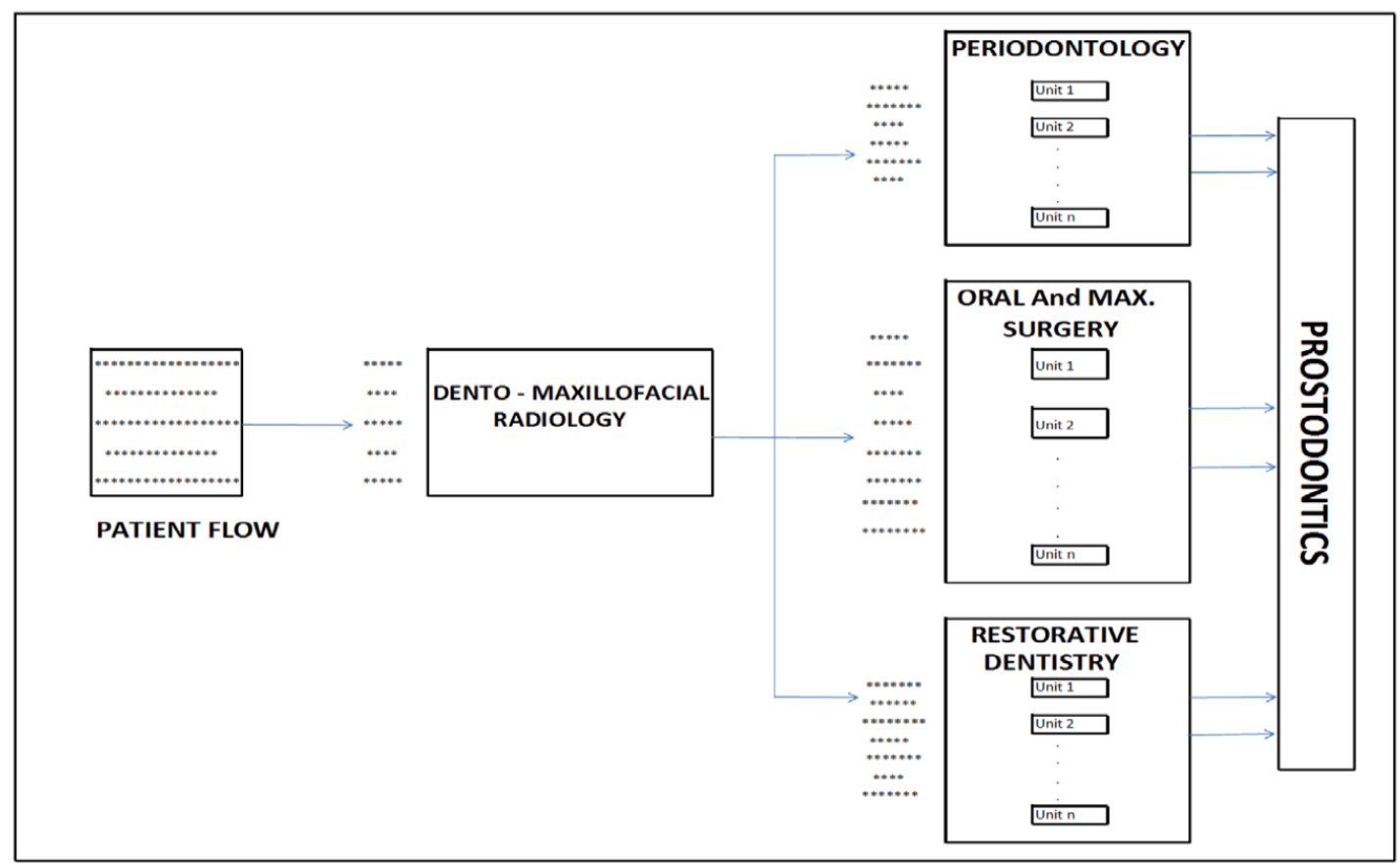

Figure 3. Proposed system for patient treatment route and queue (Tekin \& Erol, 2016)

The treatment system and appointment system which had complicated natures in the previous study are separated. With the clarification of the distribution of roles and responsibilities which used to be unclear in the process, the performance of the staff working in the hospital is improved (Tekin \& Erol, 2016). Preparation and introduction of the roadmaps which are not available previously in the hospital shortened waiting periods of the patients and efforts are paid to increase the customer satisfaction by reinforcing the quality of the hospital. To this end, existing work flows of the clinics are renewed; and the old and the new clinic work flows are revised as depicted below.

First of all, the treatment processes in the radiology department are divided into three groups. The first one is the X-raying, the second one is acceptance of patients (examination phase) and the third one is the treatment process. As this clinic functions as an umbrella covering all other departments, it is this clinic where the patients need to enter the hospital system. They may be directed to other clinic as guided by the results of the examination and the small-size treatments provided in this clinic. Although the treatment processes offered in these clinics are different from each other, the operation is standardized. The operation is divided into two processes, namely patient acceptance and treatment process; and distribution of roles and responsibilities of the personnel is clarified on the basis of the terms of references. Overall operation renewal performed by Tekin and Erol is detailed in the present study and integrated to all clinical processes. The work flows of maxillofacial Surgery Clinic renewed under these activities are presented below as Figure 5 and 6. 


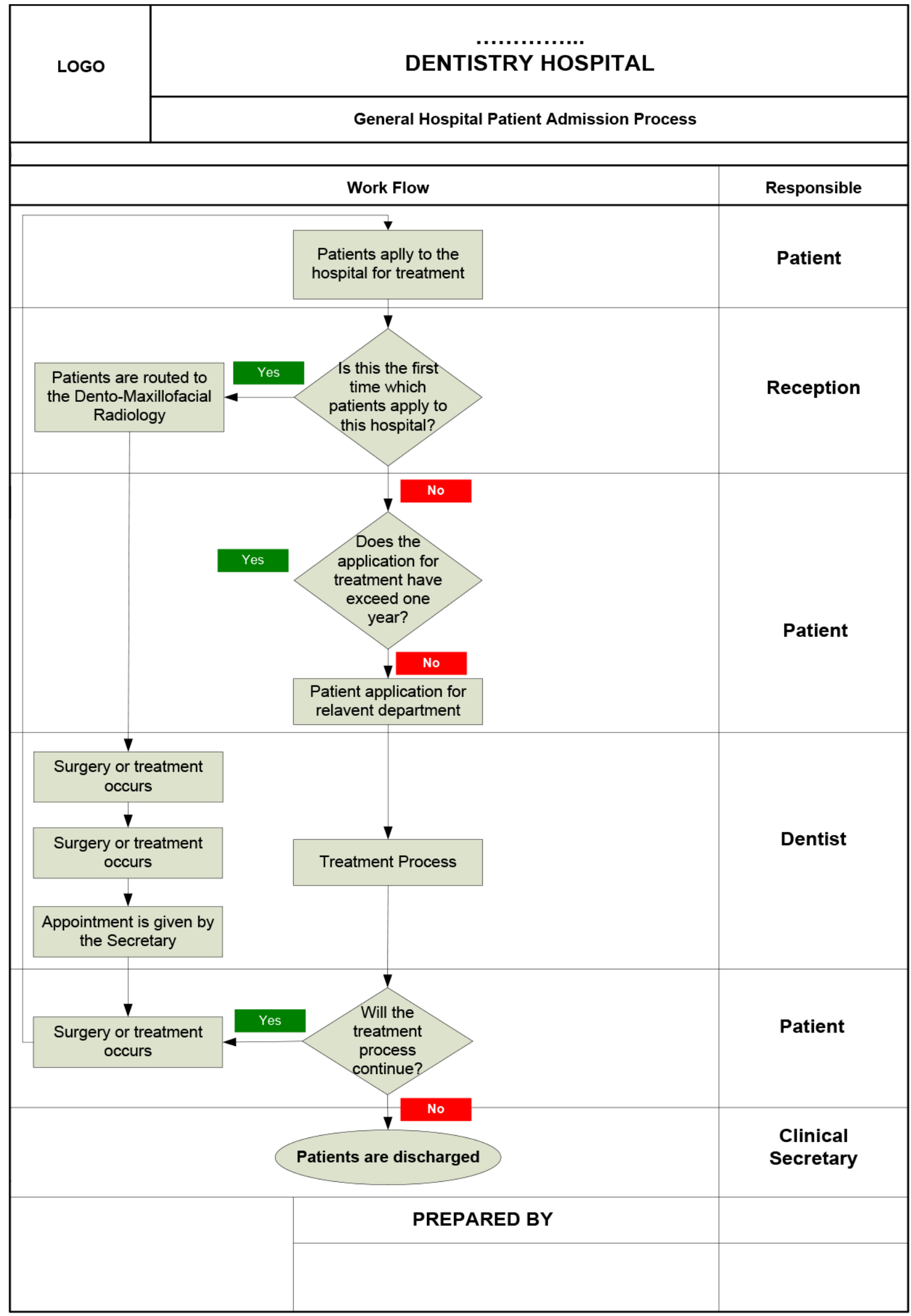

Figure 4. An example of treatment process and work flow for proposed system (Tekin \& Erol, 2016) 


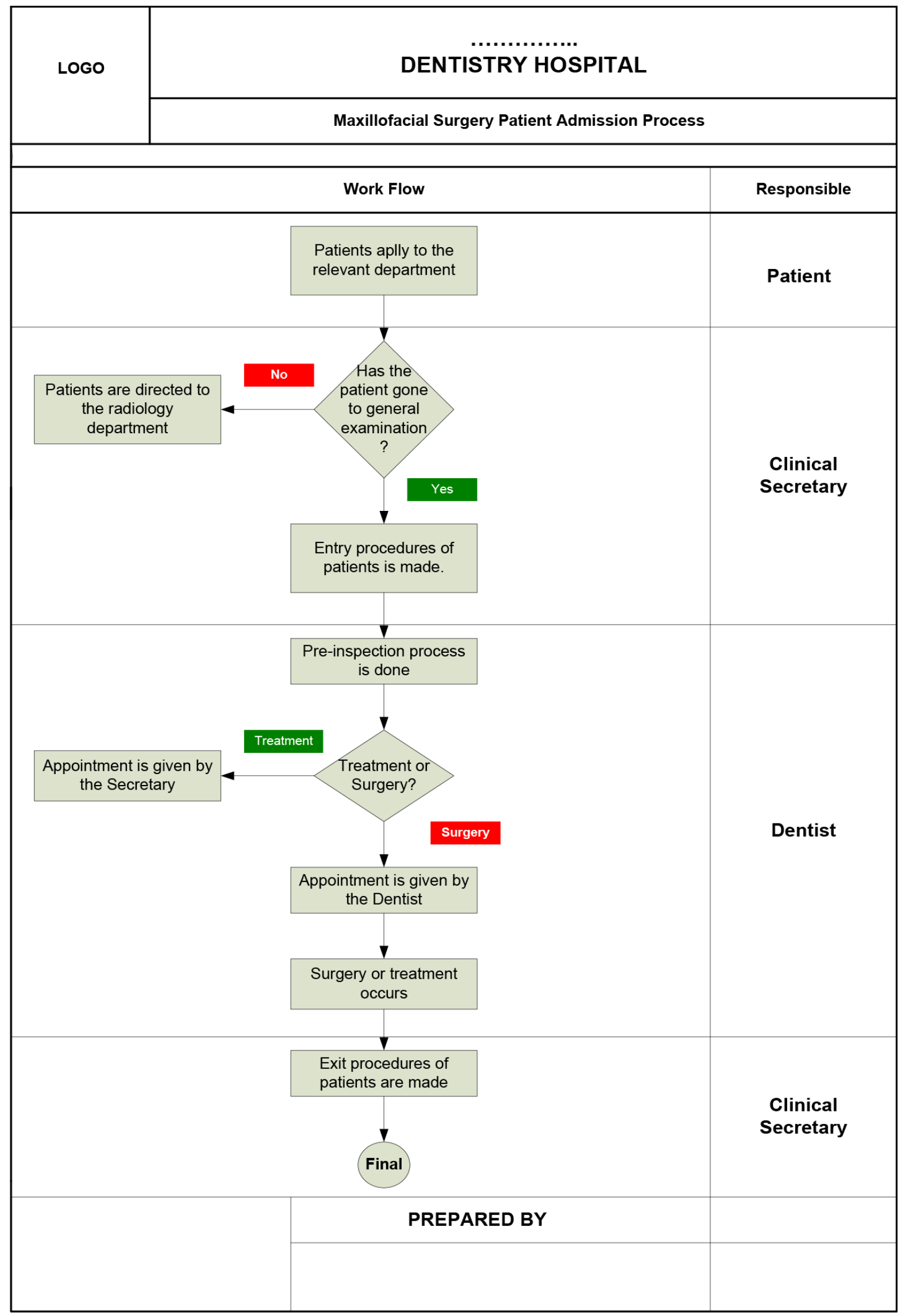

Figure 5. An example of patient admission process 


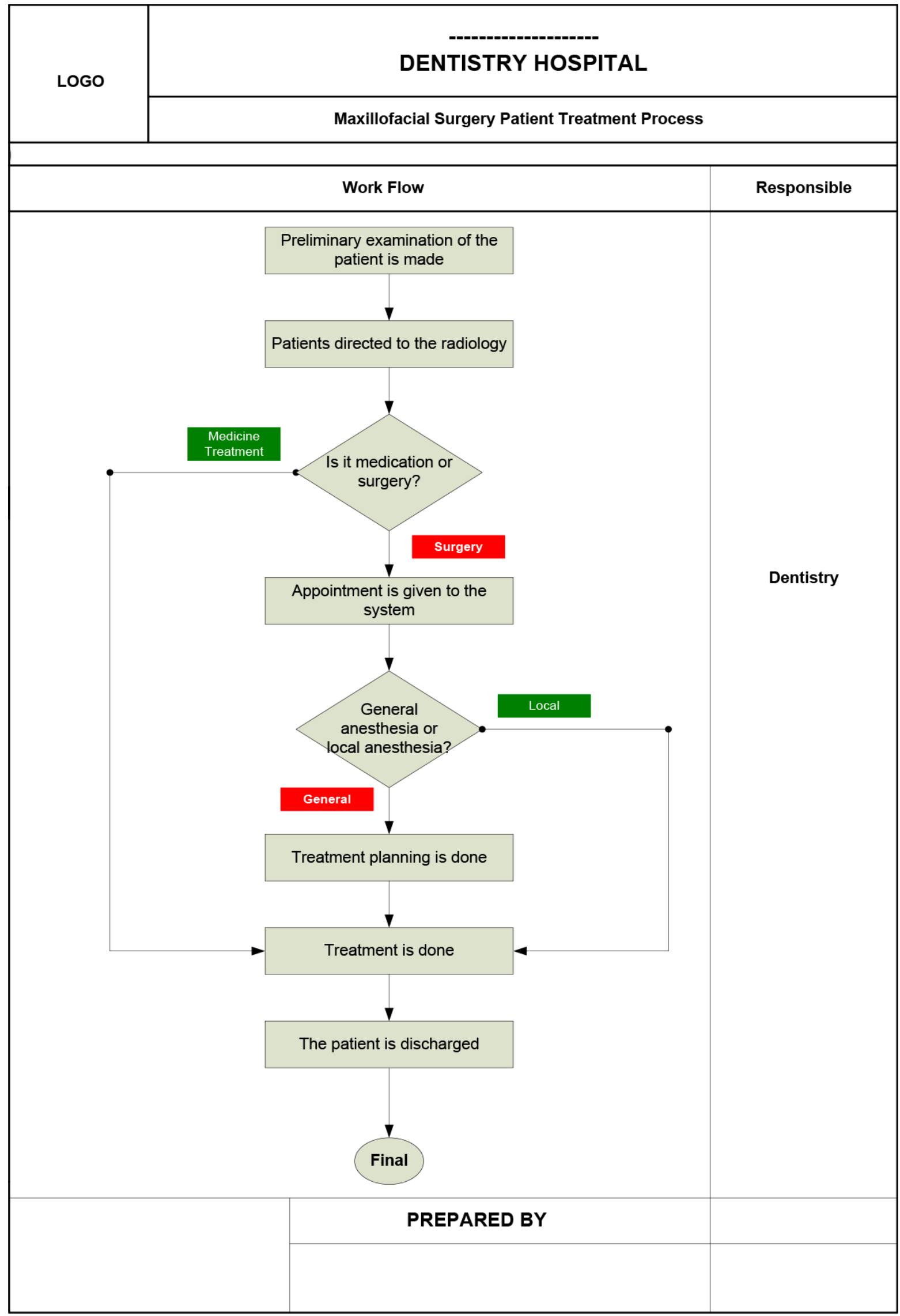

Figure 6. An example of patient treatment process 


\section{The Performance of Systems Comparison}

The present study eliminated the repetition of some processes which are not clarified in the operation cycle of the hospital prior to the present study and also the unnecessary applications made by the patients to the concerned clinics. As a result of the analysis conducted on the overall operation of the hospital, it is seen that the average period of time in which patients' treatments/processes are completed in the hospital as of the date of application is 62 days (Tekin \& Erol, 2016). This means patients are discharged from hospital in a healthy form, after their problems are solved, in approximately 2 months, irrespective of the emergency degree of their condition. Although dental problems are not vital by nature, there is a high possibility that it might affect our lives due to the pain they cause. This is why dental problems are encountered as emergency cases. Due to the fact that many treatment stages require urgent intervention, "the number of patient's treatment day" becomes an important performance indicator. This performance indicator is the most important parameter which might trigger the interest to be shown to competitor hospitals. For this reason, the lower number of days would increase patient satisfaction and also bring about a rise in the income amount between competing hospitals, by increasing the patient profile (Gupta \& Denton, 2008).

The renewed process roadmaps explained in the previous parts are tested for 2 months under real conditions of the hospital. Furthermore, system test phase which is performed with simulation software program included the testing of the new system in virtual environment, by operating it in 3-month periods for approximately 1000 replication. The real observations performed shed a light to the significant decrease in the number of treatment days and also in the number of complaints made to the Quality Department for the long waiting period of the treatments by $20 \%$. As a result of the system simulation conducted by using Arena 13.5 software program, it is found that the average treatment period is decreased to 53 days approximately. It is foreseen that this systematical improvement of $14.5 \%$ would impose a multiplier effect with different performance criteria and bring about more significant outcomes when implemented under the real conditions.

\subsection{Revised System: The Effects of Process Improvement Model}

Senario I: This proposed design attempted to minimize the patient loss caused by the fact that they patients are given appointments for later dates, which is one of the biggest problems encountered in the system. In addition, an emergency department is formed for the patients who applied the hospital for emergency and referred to other health institutions as there is no emergency department. These patients are examined and treated if emergency intervention is considered to be necessary. This practise decreased 
the number of patients who went out of the system without any procedure applied on them; and increased the number of patients treated and the income of the hospital as well.

Why is an emergency clinic necessary in a dental hospital? Some problems deteriorate with the multiplier effect of abovementioned constraints detailed in previous parts. Most of the times, hospitals display a weaker stance against their rivals as a result of their failure to achieve a balance between internal and external customers. The patients' tendencies towards waiting for treatment are lower in cases of emergency and severe diseases. The potential of patients lost due to absence of coordination among existing clinics reach severe number when combined with such cases.

Is it possible to solve the patient queue problem until the real treatment stage by opening a new clinic which will work independent from other clinics? It is planned that an emergency dental department to be involved in the system at this stage will include the patients who applied the dental hospital on emergency basis (but had to wait for a long time to get a treatment appointment) to the system as the first priority. In addition, this emergency department will help increase the satisfaction level of external customer whose waiting period is long between treatments to be delivered by different clinics, by performing treatments to decrease their pains (in other words support treatments through temporary solutions). Another improvement to be achieved by the emergency department may be an increase in the productivity of internal customers and alleviation in the work intensity in some clinics. Except for these potential benefits, the productivity of internal customers with high level of idle time will be increased when shifted to the emergency department, by using simulation modeling. With this new system design, it is planned that the resources in hand will be used more efficiently.

\section{Results and Discussion}

In this paper, the relevant samplings are modeled via the Arena Simulation Program (Arena 13.5). The data of the previous four months in the hospital is used in the parameters in the modelling. The system data are determined as seasonal and these characteristics are shown in the study clearly.

The dental hospitals have different clinics which are used for both education and treatment. Therefore, different type of dentists work in the clinics such as specialist dentists, assistant dentists and intern dentists (4th and 5th years students). Specialist dentists were excluded from this study, and no difference was assumed to exist between works of assistant and intern dentists. Number of assistant and intern dentists working at the different departments of the faculty is given in Table 1 (Tekin \& Erol, 2016). 


\begin{tabular}{|c|c|c|c|c|c|c|}
\hline Clinics & $\begin{array}{l}\text { Number of } \\
\text { assistants }\end{array}$ & $\begin{array}{l}\text { Number } \\
\text { of intern } \\
\text { students }\end{array}$ & $\begin{array}{c}\text { Total } \\
\text { dentist }\end{array}$ & $\begin{array}{l}\text { Capacity } \\
\text { rate of } \\
\text { dentist }\end{array}$ & $\begin{array}{l}\text { Total dental } \\
\text { units }\end{array}$ & $\begin{array}{l}\text { The number } \\
\text { of active } \\
\text { dental units }\end{array}$ \\
\hline Dento-maxillofacial radiology & 1 & 6 & 7 & $4.00 \%$ & 6 & 6 \\
\hline Periodontology & 2 & 6 & 8 & $9.00 \%$ & 21 & 18 \\
\hline Oral and maxillofacial surgery & 8 & 6 & 14 & $35.00 \%$ & 17 & 17 \\
\hline Restorative dentistry & 3 & 6 & 9 & $13.00 \%$ & 18 & 18 \\
\hline Prosthodontics & 9 & 6 & 15 & $39.00 \%$ & 18 & 18 \\
\hline
\end{tabular}

Table 1. Number of the external customers in the hospital (Tekin \& Erol, 2016)

Rate of number of patients who are daily treated at five departments, which are being tested in the system, to the total number of treated patients is given in the chart of Figure 7.

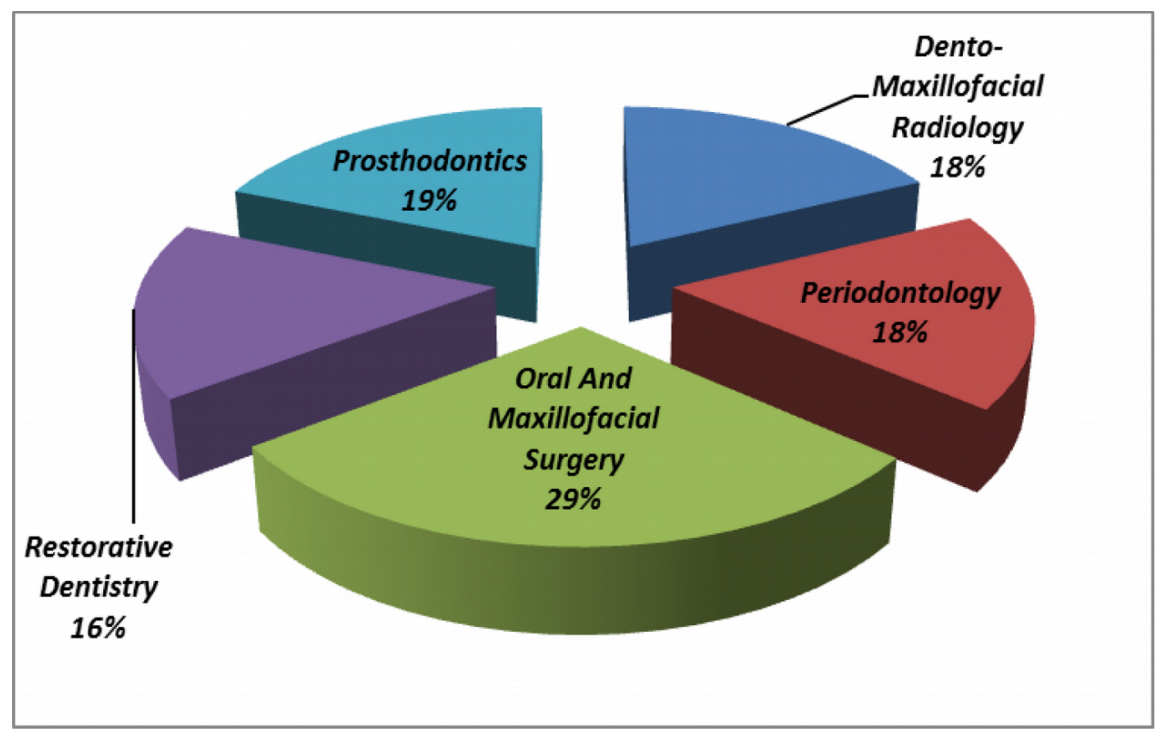

Figure 7. Clinics appointment rates in the dental hospital - for 4 months

(Tekin \& Erol, 2016)

The daily treatment amount (engagement rate) of the physicians who are providing treatment with a capacity of approximately 50-55\% (amount of physicians treating patients in the system) in the existing system increased in the improved system following the introduction of Emergency Department, in all departments, but for periodontology. It is reported that this amount decreased in periodontology deparments by negligible extent, as can be seen in Table 2 .

In a previous study, Tekin and Erol analyzed the impact imposed by the system improvement strategy only on the quantitative data of the system, number of patients treated and the number of treatment 
days. When the results obtained by this study under the guidance of process change approach are combined with those of the present study, it becomes even more apparent that the system improvements yielded positive results.

\begin{tabular}{|c|c|c|c|c|c|c|c|}
\hline $\begin{array}{l}\text { Alternative } \\
\text { scenarios / } \\
\text { departments }\end{array}$ & $\begin{array}{c}\text { Dento- } \\
\text { maxillofacial } \\
\text { radiology } \\
\text { department }\end{array}$ & $\begin{array}{c}\text { Periodontology } \\
\text { department }\end{array}$ & $\begin{array}{l}\text { Oral and } \\
\text { maxillofacial } \\
\text { surgery } \\
\text { department }\end{array}$ & $\begin{array}{l}\text { Restorative } \\
\text { dentistry } \\
\text { department }\end{array}$ & $\begin{array}{c}\text { Prosthodontics } \\
\text { department }\end{array}$ & $\begin{array}{l}\text { Emergency } \\
\text { restorative } \\
\text { dentistry } \\
\text { department }\end{array}$ & $\begin{array}{l}\text { General } \\
\text { emergency } \\
\text { treatment } \\
\text { department }\end{array}$ \\
\hline Real system & 55.00 & 52.00 & 54.00 & 57.00 & 32.00 & 0.00 & 0.00 \\
\hline $\begin{array}{l}\text { General emergency } \\
\text { treatment } \\
\text { department }\end{array}$ & 66.26 & 51.74 & 58.37 & 59.21 & 41.85 & 52.78 & 71.79 \\
\hline $\begin{array}{l}\text { Emergency } \\
\text { treatment } \\
\text { department }+30 \% \\
\text { capacity increase }\end{array}$ & 67.78 & 72.99 & 62.21 & 77.38 & 54.14 & 52.80 & 72.15 \\
\hline $\begin{array}{l}\text { Emergency } \\
\text { treatment } \\
\text { department }+50 \% \\
\text { capacity increase }\end{array}$ & 67.78 & 73.00 & 63.00 & 90.00 & 64.00 & 52.00 & 72.15 \\
\hline
\end{tabular}

Table 2. The capacity utilization rates of different suggestion processes

As shown in Figure 8, the patients prefer to go to another dental hospital because of the quene of treatment in clinics. They don't want to spend their time with waiting treatment process in this Dental Hospital. Thus, the patients relinquished not to prefer this loop in this process chart.

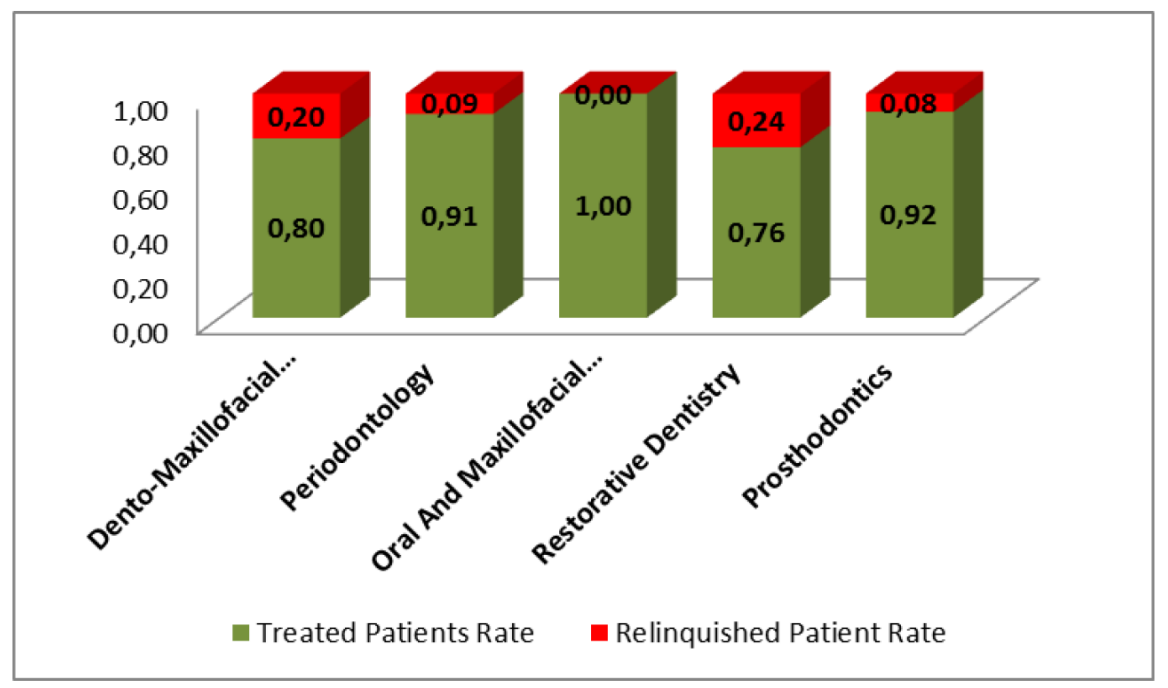

Figure 8 . The real system - rate comparison of treated and relinquished patients in the dental hospital (Tekin \& Erol, 2016) 
As can be seen in Figure 9, realization of only system improvements can solve certain critical bottlenecks; and when such improvements are reinforced by the changes in the quantitative values of the system, they together increase the improvement rates even more.

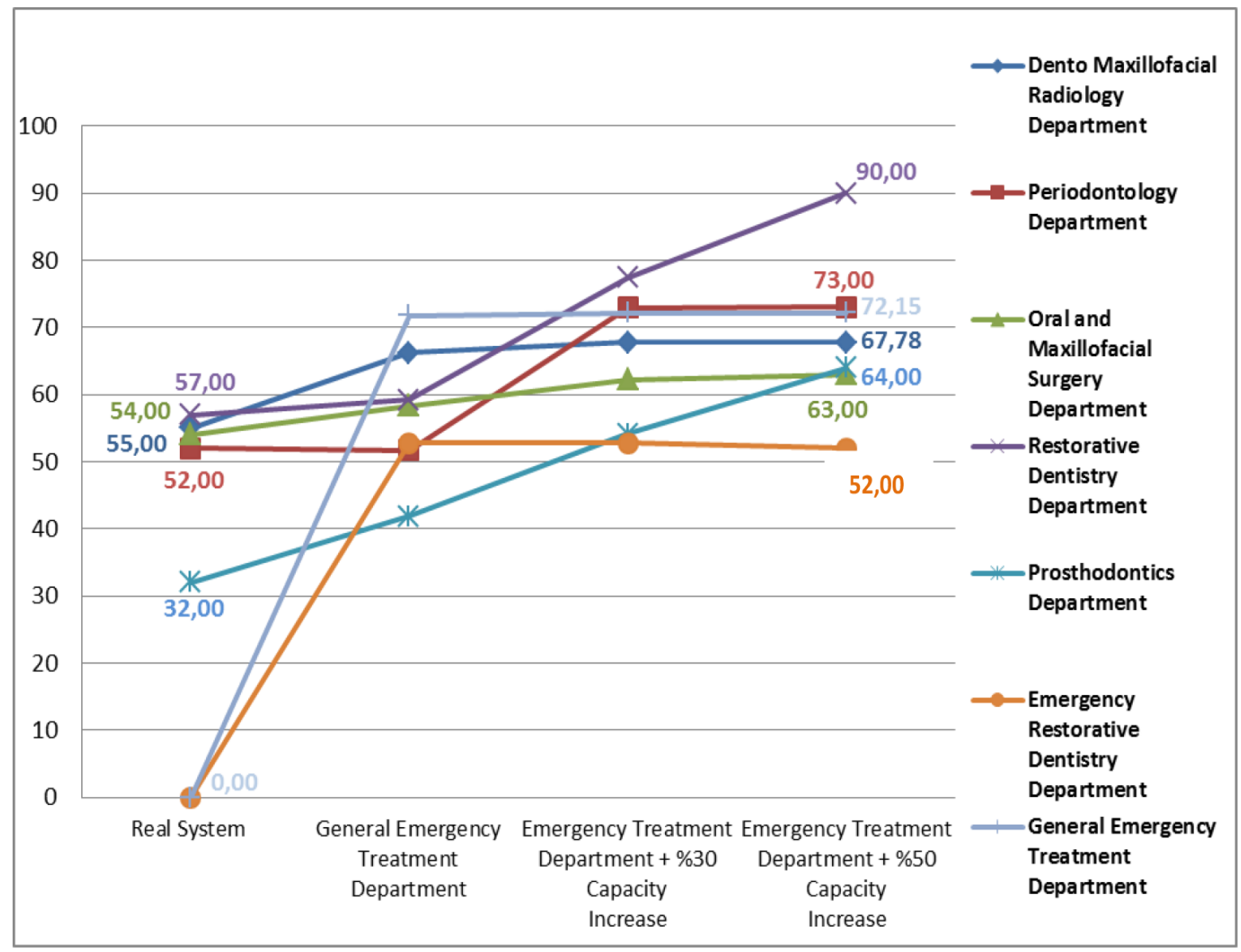

Figure 9. The enhancement of dentists utilization rates for new proposed system

With the introduction of the Emergency System in the hospital, the rate of patients who decided not to have the treatment, which is one of the most important problems of the system, decreased to $0 \%$ in the Radiology Department. This rate increased from $8.9 \%$ to $17.22 \%$ in the Periondotology Department, from $0 \%$ to $0.5 \%$ in Surgery Department, from $23.6 \%$ to $30 \%$ in the Treatment Department, from $7.9 \%$ to $9 \%$ in the Prothesis Department.

A diligent analysis of the results reveals that the number of the patients that are included in the system outnumbers the number patients who are lost in the existing system as the patients who used to be referred to other health institutions before the introduction of the emergency unit are now treated. Although the number of patients who decided not to have the treatment increased in many departments proportionally, following the implementation of the new strategy (introduction of the emergency unit). 
In the situation analysis conducted previously, it is reported that 7351 patients left the hospital in a period of 9 months. After the establishment of the emergency department, 5150 of the 7351 patients are treated in the hospital and these patients are re-gained by the hospital, thanks to the system improvements performed. Figure 10 depicts the rates of the patients who decided not to have treatment for all new system approaches.

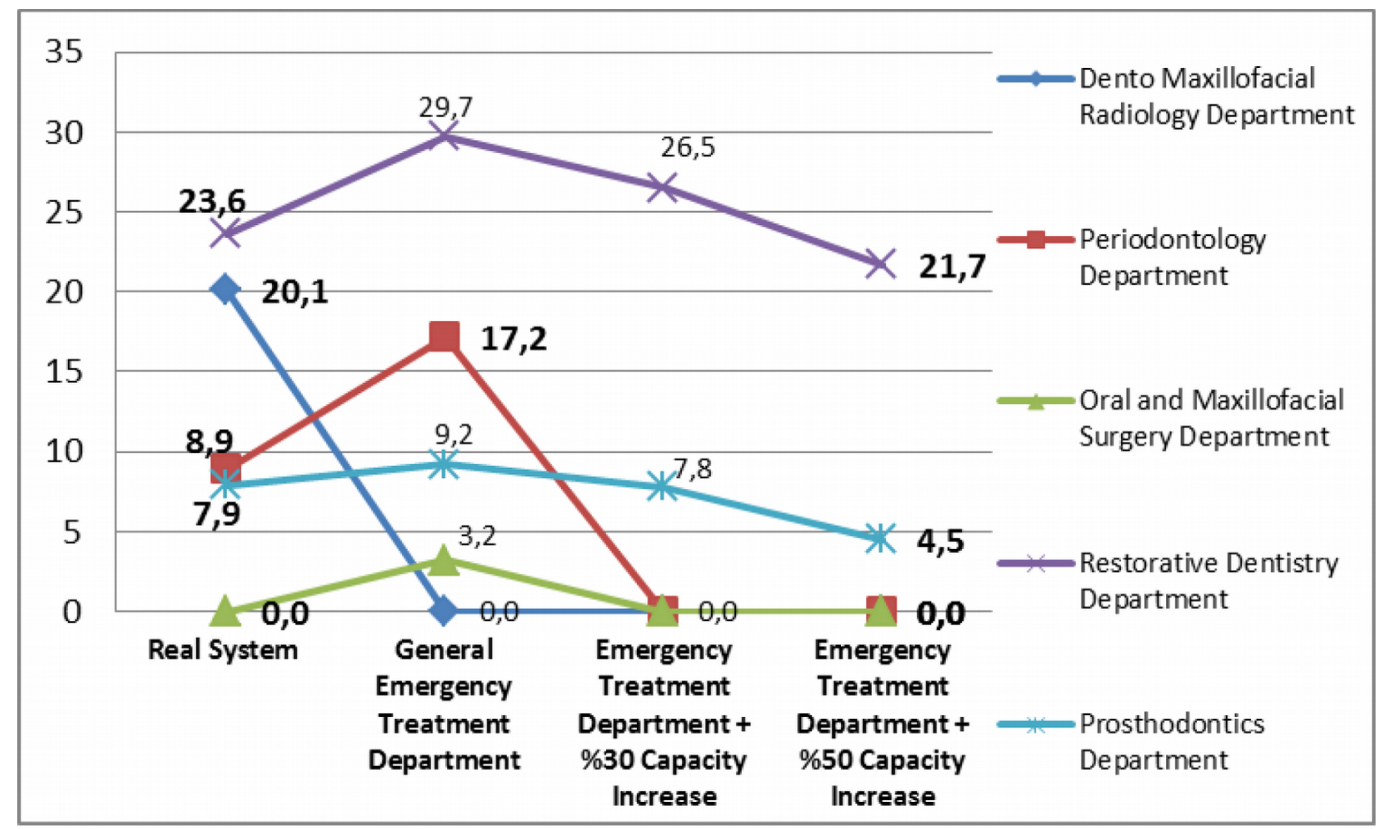

Figure 10. The rate of patient relinquishment for alternative approaches (\%)

\begin{tabular}{|c|c|c|c|c|c|c|c|c|c|}
\hline $\begin{array}{l}\text { Alternative } \\
\text { scenarios / } \\
\text { departments }\end{array}$ & $\begin{array}{c}\text { Dento- } \\
\text { maxillofacial } \\
\text { radiology }\end{array}$ & Periodontology & $\begin{array}{l}\text { Oral and } \\
\text { maxillofacia } \\
1 \text { surgery }\end{array}$ & $\begin{array}{l}\text { Restorative } \\
\text { dentistry }\end{array}$ & Prosthodontics & \begin{tabular}{|c|} 
Dento- \\
maxillofacial \\
radiology +2 \\
diferent \\
clinic \\
treatment out \\
of 3 clinics
\end{tabular} & $\begin{array}{c}\text { Dento- } \\
\text { maxillofacial } \\
\text { radiology }+3 \\
\text { diferent clinic } \\
\text { treatment out } \\
\text { of } 3 \text { clinics }\end{array}$ & $\begin{array}{c}\text { Dento- } \\
\text { maxillofacial } \\
\text { radiology }+3 \\
\text { diferent clinic } \\
\text { treatment out } \\
\text { of } 3 \text { clinics }+ \\
\text { prosthodontics }\end{array}$ & $\begin{array}{l}\text { The } \\
\text { average of } \\
\text { patient } \\
\text { treatment } \\
\text { process }\end{array}$ \\
\hline Real system & 25 & 8 & 1 & 43 & 12 & 41 & 63 & 63 & 53 \\
\hline $\begin{array}{l}\text { General } \\
\text { emergency } \\
\text { treatment } \\
\text { department }\end{array}$ & 5 & 15 & 5 & 46 & 17 & 31 & 55 & 60 & 48 \\
\hline $\begin{array}{l}\text { Emergency } \\
\text { treatment } \\
\text { department } \\
+30 \% \\
\text { capacity } \\
\text { increase }\end{array}$ & 3 & 3 & 3 & 38 & 15 & 21 & 51 & 54 & 41 \\
\hline $\begin{array}{l}\text { Emergency } \\
\text { treatment } \\
\text { department } \\
+50 \% \\
\text { capacity } \\
\text { increase }\end{array}$ & 3 & 3 & 2 & 33 & 13 & 20 & 48 & 53 & 41 \\
\hline
\end{tabular}

Table 3. The impact of alternative scenarios which on the number of treatment days 
Structuring of Emergency Department in the hospital shortened the duration in which the patients wait to receive an appointment date in the existing system. However, the appointment capacity of the departments except for the emergency department is increased by $30 \%$ firstly, then by $50 \%$. The results are analyzed. The analysis indicates that the impacts of the qualitative improvements which are conducted in addition to the process improvements are higher in the form of a multiplier effect. Another conclusion drawn from the analysis is that increasing the appointment capacity significantly decreased the waiting period in the system. This data is presented in detail in Table 3 and their comparisions are presented in Figure 11.

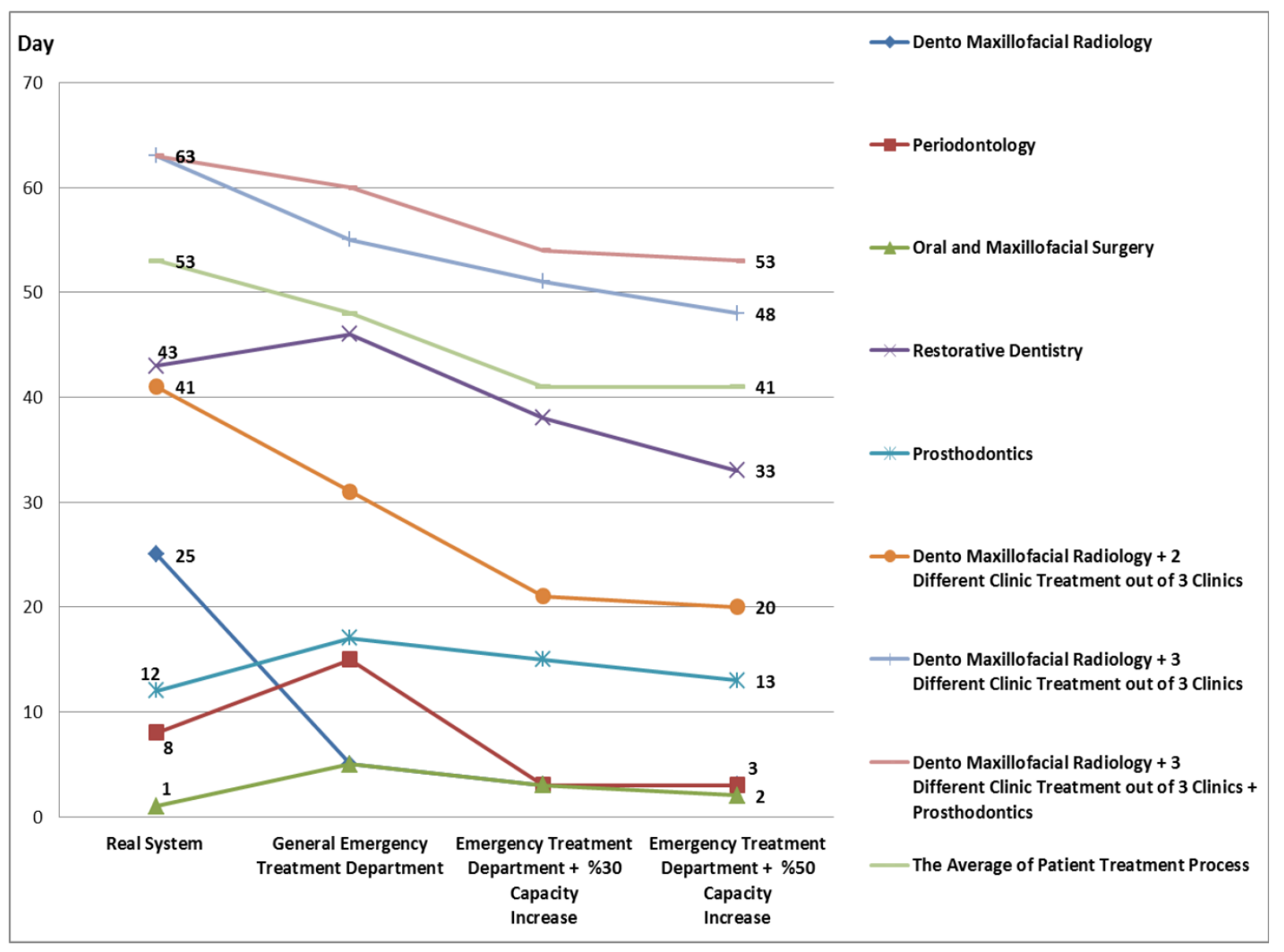

Figure 11. The impact of different alternative senarios for patient treatment days

The comparisions showed that the impact of capacity increase along with the process improvements on the treatment duration is stronger and that this duration is reduced to 0 in many departments.

Moreover, all these tables and figures show that the impact of different process types used in proposed system can improve the patient satisfaction. And also, making balace between treatment time and patient waiting time can increase internal customers' efficiency. Because before the proposed system 
implementation, some of the clinics dentists have to wait the patients for treatment although some of the clinics work continously. So almost all idle time is decreased via new system flow.

\section{Conclusion}

In this research, the appointment scheduling problem has been simulated with real data to solve with taking into account capacity planning problem. Multi-stage patient appointments and complex treatment processes complicates the process of transition and flow lines. We apply Arena Simulation Programme to solve the complicated dental system. We present a process improvement approach has provided to cut the duration of treatment. And also, we show that the solutions thus found satisfies internal and external customers in the system hence the proposed system is optimal.

The process improvements on the treatment duration is stronger and this duration of waiting is reduced to 0 in many departments. Additionally, the new designed treatment flow is optimizing equipment requirements, capacity usage of both equipments and the external customers, patient admission rate and also aiting times of internal customers in real system.

The meaningful results are obtained via proposed two separate scenario analysis improved system efficiency considering the optimization of treatment time. The proposed system methodology is easy to implement and can be used for simultaneously deciding the management mechanism of health systems for both sides of customers. The proposed system redesigned by combining simulation and quality management techniques is tested by real data via the biggest dentistry hospital in Turkey. Designing the treatment processes and general system of services with seasonality of data and multiple-hospital competition would be an interesting direction for future research. Furthermore, replenishment of appointment scheduling in uncertainity such as emergency treatments would be a significant future research. Another challenging extension would be to include cross-price elasticity of treatment departments.

\section{Acknowledgement}

The authors would like to acknowledge the Scientific Research Project Unit of Cukurova University, Turkey (MMF-2010-YL20) for full financial support. 


\section{References}

Alparslan, F., Cağcağ, O., \& Eğrioğlu, E. (2010). Ondokuz Mayıs Üniversitesi Tıp Fakültesi Beyin Cerrahisi Polikliniğginde Simülasyon Yardımıyla Hasta Bekleme Süresinin Azaltılması. 7. İstatistik Günleri Semposyumu Bildiriler Kitabı. 89-94.

Ceschia, S., \& Schaerf, A. (2011). Local search and lower bounds for the patient admission scheduling problema. The IX Metaheuristics International Conference (MIC).

Cohcran, J.K., \& Bharti, A. (2006). A multi-stage stochastic methodology for whole hospital bed planning under peak loading. Int. J. Industrial and System Engineering, 1(1/2), 8-36.

https://doi.org/10.1504/IJISE.2006.009048

Dacosta, M., Baesler, F.F., \& Jahsen, H.E. (2003). The use of simulation and design of experiments for estimating maximum capacity in an emergency room. Proceedings of Winter Simulation Conference. 1903-1906.

Gupta, D., \& Denton, B. (2008). Appointment Scheduling in Health Care: Challenges and Opportunities. IIE Transactions, 40(9), 800-819, DOI: https://doi.org/10.1080/07408170802165880

Kapamara, T., Sheibani, K., Petrovic, D., Haas, O.C.L., \& Reeves, C. (2007). A Simulation of a Radiotherapy Treatment System: A Case Study of a Local Cancer Centre. Proceedings of ORP3 Meeting, Guimares. 12-15.

Kim, S.C., \& Horowitz, I. (2002). Scheduling Hospital Services: The Efficacy of Elective - Surgery Quatos. The International Journal Management Science, 30, 335-346. https://doi.org/10.1016/S0305-0483(02)000506

Kisaer, H., \& Karabacakoğlu, C. (2004). Çukurova Üniversitesi Diş Hekimliği Fakültesi Performans Analizi. Milli Prodüktivite Merkezi Yayılar, 679.

Mageshwari, G., \& Kanaga, E.G.M. (2012). A Distributed Optimized Patient Scheduling Using Partial Information. International Journey of Artificial Intelligence \& Applications (IJALA), 3(3), 83-94. https://doi.org/10.5121/ijaia.2012.3307

Nguyen, J.M., Six, P., Antonoli, D., Glemain, P., Potel, G., Lombrail, P. et al. (2005). A simple method to optimize hospital bed capacity. International Journal Of Medical Informatics, 74, 39-49. https://doi.org/10.1016/j.ijmedinf.2004.09.001 
Ogulata, S.N., \& Erol, R. (1998). A Hierarchical Multiple Criteria Mathematical Programming Approach for Scheduling General Surgery Operations in Large Hospitals. Journal of Medical Systems, 27(3), 259-270. https://doi.org/10.1023/A:1022575412017

Shao, J. (2011). Simulation Modeling and Analysis For Outpatient Scheduling. MSc Thesis.

Soyarslan, S., Karaca, G., \& Tamyuksel, K. (2010). Türk ve Amerikan Hastane Acil Servis İş Süreçlerinin Karşılaştırması - Ankara Numune Eğitim ve Araştırma Hastanesi Acil Servis Simülasyon Modeli.

Tekin, P., \& Erol, R. (2016). Modelling and Analysis of Operation and Patient Appointment Systems: A Case Study at a Dental Hospital in Turkey, UKsim - AMSS 18th International Conference on Modelling \& Simulation. https://doi.org/10.1109/UKSim.2016.44

Yalçin, M. (2009). Simulation of Emergency Department Services: Karsiyaka State Hospital Implementation. MSc Thesis.

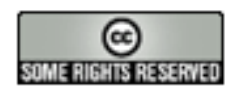

Article's contents are provided on an Attribution-Non Commercial 3.0 Creative commons license. Readers are allowed to copy, distribute and communicate article's contents, provided the author's and Journal of Industrial Engineering and Management's names are included. It must not be used for commercial purposes. To see the complete license contents, please visit http://creativecommons.org/licenses/by-nc/3.0/. 